\title{
Uniform Design and Explicit Dynamics Finite Element Analysis in Improving Permanent Deformation of an On-Road Bicycle Frame Undergoing the Drop-Frame Impact Test
}

\author{
C.K. Lee \\ Department of Industrial Engineering and Management \\ Cheng Shiu University \\ Kaohsiung, Taiwan
}

\author{
Y.C. Cheng \\ Department of Mechanical and Automation Engineering \\ National Kaohsiung First University of Science and \\ Technology \\ Kaohsiung, Taiwan
}

\author{
J.H. Sun \\ Department of Mechanical and Automation Engineering \\ National Kaohsiung First University of Science and Technology \\ Kaohsiung, Taiwan
}

\begin{abstract}
This paper aims to apply the uniform design method and explicit dynamics finite element analysis to improve the permanent deformation of an on-road bicycle frame which undergoes the drop-frame impact test. Eight dimensional parameters of bicycle frame are selected as the control factors. The uniform design method is applied to construct a set of experiments. Each experiment denotes a specific design of frame. For each frame, the explicit dynamics finite element analysis package ANSYS/LS-DYNA is employed to simulate the drop-frame impact test and analyse the permanent deformation of bicycle frame. From all the experiments, the frame which causes the smallest permanent deformation is selected as the improved design of frame. Compared with the original design of frame which causes a permanent deformation of $5.66 \mathrm{~mm}$, the improved design causes a permanent deformation of $5.1 \mathrm{~mm}$. The rate of improvement is $9.9 \%$.
\end{abstract}

Keywords-Explicit dynamics finite element analysis; OnRoad bicycle frame; Drop-frame impact test simulation; Uniform design; ANSYS/LS-DYNA

\section{INTRODUCTION}

Recently, biking has also become a new leisure activity and bicycle is more than just a lightweight means of transportation. Therefore, effective simulation software for safety testing of a bicycle system will be of need and of use to bicycle manufacturing companies and designers.

A variety of studies on finite element analysis of a bicycle frame can be found in the literature [1-3]. The external forces acting on the bicycle frame have been taken as the simple static load during analysis. Wang et al. [1] illustrated and compared the static analysis results of the sports bicycle frame by ANSYS Workbench software and experimental findings. For optimization of bicycle frames,
Fuerle and Sienz [2] presented a bespoke optimization software framework for the design of optimal bicycle frames. Employing a two-dimensional model of the bicycle frame, Huang and Wang [3] investigated the optimization for the lightest weight of the bicycle frame using genetic algorithms. Although the optimization and design of the bicycle frame have been presented by Fuerle and Sienz [2], and Huang and Wang [3], three-dimensional models of the bicycle frames have not been considered. Moreover, the analysis and simulation of the drop-frame impact test for an on-road bicycle frame has not been investigated by ANSYS/LSDYNA software.

In this study, components of an on-road bicycle frame are introduced firstly. Secondly, the drop-frame impact test according to EN-14781 bicycle testing rule [4] is described. Thirdly, explicit dynamics finite element analysis for simulating the drop-frame impact test of bicycle frame is presented. Finally, uniform design of experiments for reducing the permanent deformation of bicycle frame undergoing the drop-frame impact test is presented.

\section{DROP-FRAME IMPACT TEST OF AN ON-ROAD BICYCLE FRAME}

The on-road bicycle frame, as shown in Figure 1, is the research subject of this paper. The frame is composed of front fork, head tube, top tube, seat tube, down tube, seat stays, and chain stays. The front fork is assembled into the head tube of the bicycle frame. A qualified bicycle frame must pass the drop-frame impact test. According to the bicycle testing rule EN-14781 [4], in the drop-frame impact test, a qualified bicycle frame is demanded to have a permanent deformation smaller than $15 \mathrm{~mm}$. Figure 2 illustrates the EN-14781 bicycle testing rule, which has the following steps. First of all, a mass of $70 \mathrm{~kg}$ is placed and 
fixed on the top of seat tube. Then, the bicycle frame is tilted counter clockwise so that the centre of the mass is vertically above rear axle. Next, the bicycle frame is released statically. Due to the gravity effect, the bicycle frame will rotate clockwise about the rear axle and impact the steel anvil. After impact, the frame will vibrate for a while. When the front fork has come to rest on the steel anvil, the permanent deformation along the longitudinal direction of the frame is measured as the result of the test.

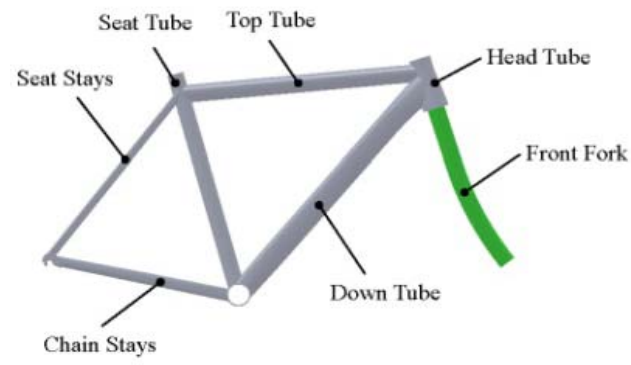

FIGURE I.THE STRUCTURE OF AN ON-ROAD BICYCLE FRAME.

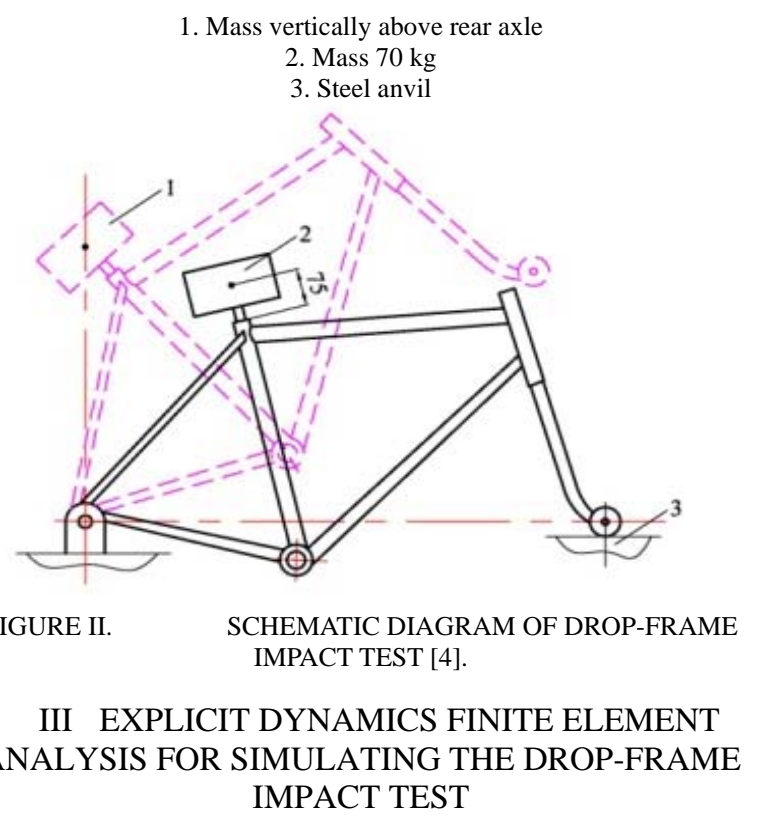

Since the impact time between the front fork and the steel anvil is very short, the explicit dynamics finite element analysis is employed to simulate the drop-frame impact test. The analysis contains 3 stages: pre-processing, processing, and post-processing stages. In pre-processing stage, the solid model and finite element model of bicycle frame are created. The solid model is created in SolidWorks while the finite element model is created in ANSYS. The finite element model includes qualified finite elements, materials properties, boundary conditions, and contact surface setting. Materials properties of the bicycle frame studied herein are shown in Table 1. Boundary conditions are applied so that the bicycle frame can only rotate freely about the rear axle. Values of dimensions of the original design of bicycle frame are shown in Table 2. In processing stage, the finite element model is solved by ANSYS/LS-DYNA. In post-processing stage, the time responses of bicycle frame are observed. The maximum permanent deformation of bicycle frame along the longitudinal direction of the frame is regarded as the output of the analysis. To ensure that the size of elements is appropriate, the mesh convergence analysis must be carried out. Figure 3 shows the results of mesh convergence analysis. The output of analysis is converged as long as the size is smaller than $0.00514 \mathrm{~mm}$. In this study, the element size is set to be $0.005 \mathrm{~mm}$. Figure 4 shows the distribution of permanent deformation of bicycle frame along the longitudinal direction of the frame. The maximum permanent deformation of the bicycle frame along the longitudinal direction is $5.66 \mathrm{~mm}$.

TABLE I. MATERIALS PROPERTIES OF THE BICYCLE FRAME.

\begin{tabular}{|l|c|c|c|c|c|c|}
\hline Body & Material & $\begin{array}{c}\text { Young' } \\
\mathrm{s} \\
\text { Modulu } \\
\mathrm{s}(\mathrm{Pa})\end{array}$ & $\begin{array}{c}\text { Poisson' } \\
\text { s Ratio }\end{array}$ & $\begin{array}{c}\text { Densit } \\
\mathrm{y} \\
\left(\mathrm{kg} / \mathrm{m}^{3}\right. \\
)\end{array}$ & $\begin{array}{c}\text { Yield } \\
\text { Strengt } \\
\mathrm{h}(\mathrm{Pa})\end{array}$ & $\begin{array}{c}\text { Tangent } \\
\text { Modulu } \\
\mathrm{s}(\mathrm{Pa})\end{array}$ \\
\hline $\begin{array}{l}\text { Fram } \\
\mathrm{e}\end{array}$ & $\begin{array}{c}\text { Aluminu } \\
\mathrm{m} \text { Alloy }\end{array}$ & $\begin{array}{c}7.1 \times 10^{1} \\
0\end{array}$ & 0.33 & 2770 & $2.8 \times 10^{8}$ & $5 \times 10^{8}$ \\
\hline $\begin{array}{l}\text { Front } \\
\text { fork }\end{array}$ & $\begin{array}{c}\text { Stainless } \\
\text { Steel }\end{array}$ & $\begin{array}{c}7.1 \times 10^{1} \\
0\end{array}$ & 0.3 & 7850 & - & - \\
\hline $\begin{array}{l}\text { Steel } \\
\text { anvil }\end{array}$ & $\begin{array}{c}\text { Stainless } \\
\text { Steel }\end{array}$ & $\begin{array}{c}7.1 \times 10^{1} \\
0\end{array}$ & 0.3 & 7850 & - & - \\
\hline
\end{tabular}

TABLE II. VALUES OF DIMENSIONS OF THE ORIGINAL DESIGN OF BICYCLE FRAME.

\begin{tabular}{ccc}
\hline Dimension & Symbol & Value(mm) \\
\hline Length of $1^{\text {st }}$ section of top tube & TT-1L & 40.00 \\
Thickness of $1^{\text {st }}$ section of top tube & TT-1t & 1.20 \\
Length of $5^{\text {th }}$ section of top tube & TT-5L & 61.26 \\
Thickness of $5^{\text {th }}$ section of top tube & TT-5t & 1.10 \\
Length of $1^{\text {st }}$ section of down tube & DT-1L & 140.00 \\
Thickness of $1^{\text {st }}$ section of down tube & DT-1t & 1.80 \\
Length of $5^{\text {th }}$ section of down tube & DT-5L & 60.00 \\
Thickness of $5^{\text {th }}$ section of down tube & DT-5t & 1.35 \\
\hline
\end{tabular}

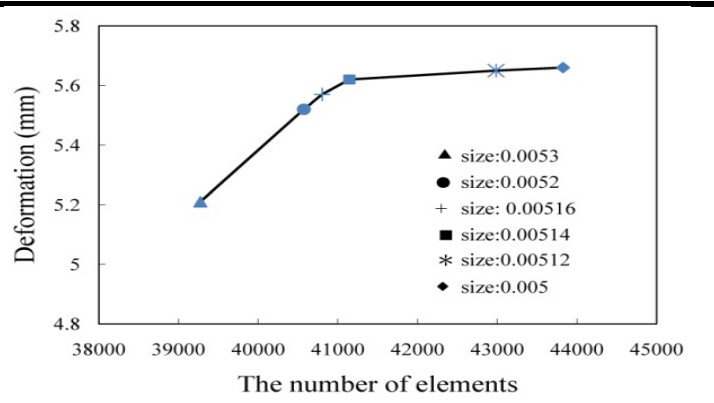

FIGURE III
HE RESULT OF MESH CONVERGENCE ANALYSIS. 


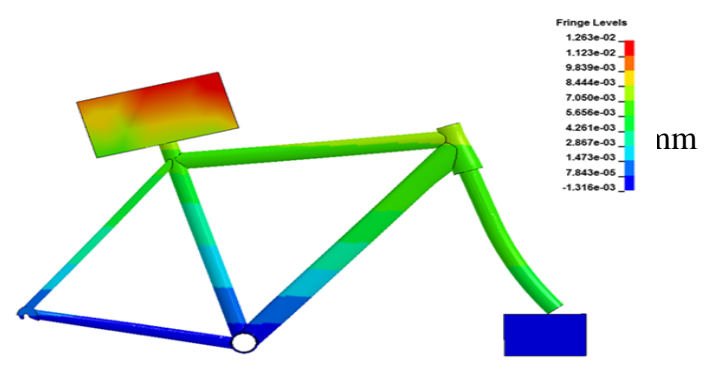

FIGURE IV. THE DISTRIBUTION OF PERMANENT DEFORMATION OF BICYCLE FRAME ALONG THE LONGITUDINAL DIRECTION OF THE FRAME.

\section{UNIFORM DESIGN OF EXPERIMENTS FOR REDUCING PERMANENT DEFORMATION}

Figure 5 shows the positions of control factors. The onroad bicycle frame studied in this paper has eight dimensional control factors: length of $1^{\text {st }}$ section of top tube (TT-1L), thickness of $1^{\text {st }}$ section of top tube (TT-1t), length of $5^{\text {th }}$ section of top tube (TT-5L), thickness of $5^{\text {th }}$ section of top tube (TT-5t), length of $1^{\text {st }}$ section of down tube (DT-1L), thickness of $1^{\text {st }}$ section of down tube (DT-1t), length of $5^{\text {th }}$ section of down tube (DT-5L), thickness of $5^{\text {th }}$ section of down tube (DT-5t). Information of control factors are shown in Table 3. Since all factors are continuous, the design space is a continuous space. For a continuous design space, design points are infinite and evaluation of all design points is impossible. Therefore, this study applies the uniform design method to sample a set of experimental points. The uniform design method is proposed by Fang [5] and Wang and Fang [6]. Belonging with space filling design methods, the uniform design method is able to construct a set of experimental points uniformly scattered in the continuous design space. Unlike the orthogonal design method, the uniform design method only considers the uniform distribution rather than the symmetrical comparability of experimental points. This study selects the uniform table $\mathrm{U}_{18}^{*}\left(18^{11}\right)$ to construct 18 experiments as the computational resource is limited. As shown in Table 4, the uniform table $\mathrm{U}_{18}^{*}\left(18^{11}\right)$ has 18 rows and 11 columns. Every column contains 18 numbers, from 1 to 18, denoting the levels of factors. According to the use table of $\mathrm{U}_{18}^{*}\left(18^{11}\right)$, columns 1 , 4, 5, 6, 7, 8, 9 and 11 are employed to construct the experiments because the bicycle frame just has eight control factors. The constructed experiments are shown in Table 5.
Each experiment denotes a specific design of bicycle frame. The geometric solid model of bicycle frame is created by using SolidWorks. The behaviour of bicycle frame undergoing the drop-frame impact test is simulated by using ANSYS/LS-DYNA. As the minimum permanent deformation occurs at the $2^{\text {nd }}$ experiment, the bicycle frame in the $2^{\text {nd }}$ experiment is regarded as the improved design of frame. The original design of frame causes a permanent deformation of $5.66 \mathrm{~mm}$ while the improved design of frame causes a permanent deformation of $5.1 \mathrm{~mm}$.

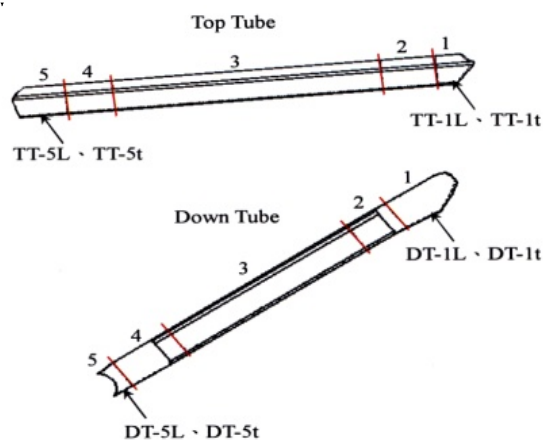

FIGURE V. $\quad$ EIGHT CONTROL FACTORS OF THE FRAME.

TABLE III. INFORMATION OF THE CONTROL FACTORS.

\begin{tabular}{|c|c|c|c|}
\hline Control factor & Symbol & $\begin{array}{l}\text { Lower } \\
\text { bound } \\
(\mathrm{mm})\end{array}$ & $\begin{array}{l}\text { Upper } \\
\text { bound } \\
(\mathrm{mm})\end{array}$ \\
\hline Length of $1^{\text {st }}$ section of top tube & TT-1L & 20.00 & 80.00 \\
\hline $\begin{array}{c}\text { Thickness of } 1^{\text {st }} \text { section of top } \\
\text { tube }\end{array}$ & TT-1t & 0.80 & 1.60 \\
\hline Length of $5^{\text {th }}$ section of top tube & TT-5L & 21.26 & 81.26 \\
\hline $\begin{array}{c}\text { Thickness of } 5^{\text {th }} \text { section of top } \\
\text { tube }\end{array}$ & TT-5t & 0.70 & 1.50 \\
\hline Length of $1^{\text {st }}$ section of down tube & DT-1L & 80.00 & 180.00 \\
\hline $\begin{array}{c}\text { Thickness of } 1^{\text {st }} \text { section of down } \\
\text { tube }\end{array}$ & DT-1t & 1.40 & 2.20 \\
\hline $\begin{array}{l}\text { Length of } 5^{\text {th }} \text { section of down tube } \\
\text { Thickness of } 5^{\text {th }} \text { section of down }\end{array}$ & DT-5L & 20.00 & 80.00 \\
\hline & DT-5t & 0.95 & 1.75 \\
\hline
\end{tabular}

TABLE IV. THE UNIFORM TABLE $\mathrm{U}_{18}^{*}\left(18^{11}\right)$.

\begin{tabular}{cccccccccccc}
\hline Exp. & 1 & 2 & 3 & 4 & 5 & 6 & 7 & 8 & 9 & 10 & 11 \\
\hline 1 & 1 & 3 & 4 & 5 & 6 & 7 & 8 & 9 & 11 & 15 & 16 \\
2 & 2 & 6 & 8 & 10 & 12 & 14 & 16 & 18 & 3 & 11 & 13 \\
3 & 3 & 9 & 12 & 15 & 18 & 2 & 5 & 8 & 14 & 7 & 10 \\
4 & 4 & 12 & 16 & 1 & 5 & 9 & 13 & 17 & 6 & 3 & 7 \\
5 & 5 & 15 & 1 & 6 & 11 & 16 & 2 & 7 & 17 & 18 & 4 \\
6 & 6 & 18 & 5 & 11 & 17 & 4 & 10 & 16 & 9 & 14 & 1 \\
7 & 7 & 2 & 9 & 16 & 4 & 11 & 18 & 6 & 1 & 10 & 17 \\
8 & 8 & 5 & 13 & 2 & 10 & 18 & 7 & 15 & 12 & 6 & 14 \\
9 & 9 & 8 & 17 & 7 & 16 & 6 & 15 & 5 & 4 & 2 & 11 \\
10 & 10 & 11 & 2 & 12 & 3 & 13 & 4 & 14 & 15 & 17 & 8 \\
11 & 11 & 14 & 6 & 17 & 9 & 1 & 12 & 4 & 7 & 13 & 5
\end{tabular}




\begin{tabular}{cccccccccccc}
12 & 12 & 17 & 10 & 3 & 15 & 8 & 1 & 13 & 18 & 9 & 2 \\
13 & 13 & 1 & 14 & 8 & 2 & 15 & 9 & 3 & 10 & 5 & 18 \\
14 & 14 & 4 & 18 & 13 & 8 & 3 & 17 & 12 & 2 & 1 & 15 \\
15 & 15 & 7 & 3 & 18 & 14 & 10 & 6 & 2 & 13 & 16 & 12 \\
16 & 16 & 10 & 7 & 4 & 1 & 17 & 14 & 11 & 5 & 12 & 9 \\
17 & 17 & 13 & 11 & 9 & 7 & 5 & 3 & 1 & 16 & 8 & 6 \\
18 & 18 & 16 & 15 & 14 & 13 & 12 & 11 & 10 & 8 & 4 & 3 \\
\hline
\end{tabular}

TABLE V.THE CONSTRUCTED EXPERIMENTS AND THE RESULTS OF ANALYSIS.

\begin{tabular}{|c|c|c|c|c|c|c|c|c|c|}
\hline No. & $\begin{array}{l}\text { TT-1L } \\
\text { (mm) }\end{array}$ & $\begin{array}{l}\text { TT-1t } \\
(\mathrm{mm})\end{array}$ & $\begin{array}{l}\text { TT-5L } \\
\text { (mm) }\end{array}$ & $\begin{array}{l}\text { TT-5t } \\
(\mathrm{mm})\end{array}$ & $\begin{array}{l}\text { DT-1L } \\
(\mathrm{mm})\end{array}$ & $\begin{array}{l}\text { DT-1t } \\
(\mathrm{mm})\end{array}$ & $\begin{array}{c}\text { DT-5L } \\
(\mathrm{mm})\end{array}$ & $\begin{array}{l}\text { DT-5t } \\
(\mathrm{mm})\end{array}$ & $\begin{array}{c}\text { Permanent } \\
\text { Deformation } \\
(\mathrm{mm})\end{array}$ \\
\hline 1 & 20.00 & 0.99 & 38.91 & 0.98 & 121.18 & 1.78 & 55.29 & 1.66 & 5.64 \\
\hline 2 & 23.53 & 1.22 & 60.08 & 1.31 & 168.24 & 2.20 & 27.06 & 1.51 & 5.10 \\
\hline 3 & 27.06 & 1.46 & 81.26 & 0.75 & 103.53 & 1.73 & 65.88 & 1.37 & 6.02 \\
\hline 4 & 30.59 & 0.80 & 35.38 & 1.08 & 150.59 & 2.15 & 37.65 & 1.23 & 5.28 \\
\hline 5 & 34.12 & 1.04 & 56.55 & 1.41 & 85.88 & 1.68 & 76.47 & 1.09 & 5.43 \\
\hline 6 & 37.65 & 1.27 & 77.73 & 0.84 & 132.94 & 2.11 & 48.24 & 0.95 & 5.35 \\
\hline 7 & 41.18 & 1.51 & 31.85 & 1.17 & 180.00 & 1.64 & 20.00 & 1.70 & 5.17 \\
\hline 8 & 44.71 & 0.85 & 53.02 & 1.50 & 115.29 & 2.06 & 58.82 & 1.56 & 5.27 \\
\hline 9 & 48.24 & 1.08 & 74.20 & 0.94 & 162.35 & 1.59 & 30.59 & 1.42 & 5.18 \\
\hline 10 & 51.76 & 1.32 & 28.32 & 1.26 & 97.65 & 2.01 & 69.41 & 1.28 & 5.84 \\
\hline 11 & 55.29 & 1.55 & 49.50 & 0.70 & 144.71 & 1.54 & 41.18 & 1.14 & 6.35 \\
\hline 12 & 58.82 & 0.89 & 70.67 & 1.03 & 80.00 & 1.96 & 80.00 & 1.00 & 5.57 \\
\hline 13 & 62.35 & 1.13 & 24.79 & 1.36 & 127.06 & 1.49 & 51.76 & 1.75 & 5.30 \\
\hline 14 & 65.88 & 1.36 & 45.97 & 0.79 & 174.12 & 1.92 & 23.53 & 1.61 & 6.36 \\
\hline 15 & 69.41 & 1.60 & 67.14 & 1.12 & 109.41 & 1.45 & 62.35 & 1.47 & 5.47 \\
\hline 16 & 72.94 & 0.94 & 21.26 & 1.45 & 156.47 & 1.87 & 34.12 & 1.33 & 5.37 \\
\hline 17 & 76.47 & 1.18 & 42.44 & 0.89 & 91.76 & 1.40 & 72.94 & 1.19 & 5.75 \\
\hline 18 & 80.00 & 1.41 & 63.61 & 1.22 & 138.82 & 1.82 & 44.71 & 1.04 & 5.27 \\
\hline
\end{tabular}

\section{$\mathrm{V}$ CONCLUSIONS}

By applying the uniform design method and the explicit dynamics finite element analysis package ANSYS/LSDYNA, this study has obtained an improved design of frame of an on-road bicycle undergoing the drop-frame impact test. The original frame has a permanent deformation of $5.66 \mathrm{~mm}$ while the improved frame has a permanent deformation of $5.1 \mathrm{~mm}$. The rate of improvement is $9.9 \%$. The future work of this study is to employ the surrogate modelling technique and optimization algorithm to advance the rate of improvement.

\section{REFERENCE}

[1] Wang J.H., Zhao J.N., Zhao Y.S., Wang Z. \& Guo D.L., Simulation about Sports Bicycle Frame Based on the Experiments, Applied Mechanics and Materials, 37-38, pp. 1142-1147, 2010.

[2] Fuerle F. \& Sienz J., Decomposed Surrogate Based Optimization of Carbon-Fiber Bicycle Frames using Optimum Latin Hypercubes for Constrained Design Spaces, Computers and Structures, 119, pp. 48-59, 2013.
[3] Huang Y.M. \& Wang K.J., Optimization of Bicycle Frames using Genetic Algorithms, Proceedings of the ASME 2007 International Design Engineering Technical Conferences and Computers and Information in Engineering Conference, 6, pp. 325-334, 2008.

[4] European Standard, EN14781: Racing Bicycles - Safety Requirements and Test Methods, 2005.

[5] Fang K.T., The Uniform Design: Application of Number-Theoretic Methods in Experimental Design, Acta Mathematicae Applicatae Sinica, 3, pp. 363-372, 1980.

[6] Wang Y. \& Fang K.T., A Note on Uniform Distribution and Experiment Design, KEXUE TONGBAO, 26(6), pp. 485-489, 1981. 